\title{
Transmissible mink encephalopathy: pathogenesis and nature of the aetiological agent
}

\author{
R. M. BARLOW \\ From Moredun Research Institute, Edinburgh
}

A number of specific encephalopathies of mink are recognized, eg, Chasteks' paralysis - an haemorrhagic destruction of grey matter associated with hypothiaminosis (Innes and Saunders, 1962) and metachromatic leucodystrophy which has a sublethal autosomal recessive transmission (Brander and Palludan, 1965).

The present paper concerns a disease characterized by spongy transformation of grey matter which, experimentally, may be readily transmitted to healthy mink by the injection of suspensions of tissues from affected animals. To distinguish this condition from others, Marsh, Burger, and Hanson (1969) have proposed the name 'transmissible mink encephalopathy'. The disease conforms to the criteria for 'slow infections' (Sigurdsson, 1954) and has features in common with scrapie in sheep, kuru, and in man CreutzfeldtJakob disease.

\section{History and Epidemiology}

The first observations of transmissible mink encephalopathy were in the USA in ranch mink in about 1947 and the specific nature of the disease was demonstrated some years later (Hartsough and Burger; Burger and Hartsough, 1965). Outbreaks are infrequent and only adult breeder animals, ie, over 1 year old, contract the disease and the morbidity in this class of stock may be $100 \%$. Mink kits, however, do not develop transmissible mink encephalopathy despite being housed with, suckling from, and consuming the same diet as their affected mothers. Field observations indicate that the natural disease has an incubation period of six to seven months. The clinical course lasts from two to six weeks and terminates fatally.

Adult mink are housed in individual wire cages arranged in rows in open sheds. The diet is raw fish, meat, and offals, together with cereals to which vitamin and mineral supplements are added. Mating occurs in March using one male to about four females. The gestation period averages 50 days and the young are suckled for four to six weeks, although they also share their mother's ration from about the third week. The majority of mink kits are 'pelted' in November and December when they are 6 to 7 months old, only replacement breeders for the next season being retained through the winter.

Thus there is little opportunity for horizontal transmission and little or no evidence of either horizontal or vertical transmission in naturally occurring transmissible mink encephalopathy. This situation is markedly different from scrapie in which contact transmission and maternal transmission have been amply demonstrated (Dickinson, Young, Stamp, and Renwick, 1965; Stamp, 1967; Brotherston, Renwick, Stamp, Zlotnik, and Pattison, 1968). It has been suggested that the mink may be an unnatural host for this disease and it is thought that it may be acquired from the diet. The most obvious inference is that transmissible mink encephalopathy may be a manifestation of scrapie in mink.

\section{Clinical Signs and Pathology}

The clinical signs of transmissible mink encephalopathy are insidious in onset and comprise locomotor disturbances and excitability which progress over a few weeks to ataxia characterized by stiff, jerky movements and interrupted by increasing periods of somnolence. There may be self mutilation, especially of the tail. In clinical cases mortality is $100 \%$. This clinical picture in many respects resembles that of scrapie.

At necropsy the carcase is usually dehydrated and the fat depots are depleted. The most characteristic changes are microscopic and are located in the central nervous system. There is widespread spongy transformation of the cortical and subcortical grey matter accompanied by intense astrogliosis. Degenerative changes of neurones may be observed in the cerebrum, cerebellum, and brain stem. Cytoplasmic vacuolation of brain stem neurones, which is the most characteristic feature of scrapie in sheep, goats, and first-passage mice, is prominent only in the region of the vestibular nuclei, the tegmentum of the pons and midbrain (Hartsough and Burger, 1965). 


\section{The Physico-chemical Properties of the Agent}

Some physical and chemical properties of the transmissible mink encephalopathy agent have been examined (Burger and Hartsough, 1965; Marsh and Hanson, 1969). Membrane filtration has indicated a particle size of $<50 \mathrm{~nm}$. The agent is resistant to boiling for 15 minutes and to ultraviolet light at $253.7 \mathrm{~nm}$ but it is sensitive to hot phenol and pronase, and partially sensitive to ether and to $10 \%$ formalin. These tests, though not so wide-ranging as those applied to scrapie (for review see Thormar, 1971), have not provided any basis for the differentiation of transmissible mink encephalopathy and scrapie and place the aetiology of both diseases within a narrow microbiological classification (Marsh, Burger, Eckroade, Zu Rhein, and Hanson, 1969).

\section{Immunological Properties of the Agent}

Using serum neutralization and immunofluorescent procedures, Marsh, Pan, and Hanson (1970) failed to demonstrate either specific serum antibody or immune complexes which might indicate the presence of antibrain autoantibodies. This lack of immunological response to transmissible mink encephalopathy agent accords with the findings in scrapie. In scrapie, absence of specific antibody is not accounted for by any depression of the host's immunological mechanisms (Gardiner and Marucci, 1969) indicating that the agent may lack effective antigens.

\section{Biological Properties of the Agent}

The difficulties of identifying the causal agents of transmissible mink encephalopathy and scrapie by orthodox microbiological techniques have led to the expenditure of unusual effort in attempting to determine the range of host susceptibility for each disease. These are summarized in Table I. It is surprising that attempted transmission of transmissible mink encephalopathy to sheep has not yet been reported.

Disease clinically and pathologically resembling transmissible mink encephalopathy has been induced in day-old hamsters but not 4-week-old hamsters, albino ferrets but not black ferrets (Marsh, Burger, Eckroade, $\mathrm{Zu}$ Rhein and Hanson, 1969), and squirrel monkeys (Eckroade, Zu Rhein, Marsh, and Hanson, 1970) by parenteral injection of brain tissue suspensions from affected mink. Marsh and his colleagues found typical lesions in a rhesus monkey killed after being asymptomatic for 33 months following injection; its tissues were infective for mink, producing clinical disease in four and a half months. Persistence of the agent for long periods of time in the absence of clinical or patho-

\begin{tabular}{|c|c|c|c|c|c|}
\hline \multirow{2}{*}{\multicolumn{2}{|c|}{ Host Species }} & \multicolumn{2}{|c|}{ Transmissible Mink Encephalopathy } & \multicolumn{2}{|l|}{ Scrapie } \\
\hline & & Result $^{1}$ & Authors & Result & Authors \\
\hline \multirow{4}{*}{\multicolumn{2}{|c|}{$\begin{array}{l}\text { Mink } \\
\text { Sheep } \\
\text { Goats }\end{array}$}} & - & Burger and Hartsough (1965) & $\therefore$ & Hanson et al (1971) \\
\hline & & & & .. & Cuillé and Chelle (1936) \\
\hline & & $\ldots$ & Zlotnik and Barlow (1967) & & \\
\hline & & - & Marsh, Burger, Eckroade, Zu Rhein, and Hanson (1969) & $\cdot$ & Gordon and Pattison (1957) \\
\hline \multirow{4}{*}{\multicolumn{2}{|c|}{ Mice }} & - & Marsh, Burger, Eckroade, Zu Rhein, and Hanson (1969) & & \\
\hline & & - & Hadlow and Karstad (1968) & - & Chandler (1961) \\
\hline & & $\cdots$ & Barlow and Rennie (1970) & $\cdots$ & Zlotnik (1961) \\
\hline & & - & Dickinson, Fraser, and Meikle (1972) & & \\
\hline \multirow{2}{*}{\multicolumn{2}{|c|}{ Rats }} & - & Marsh, Burger, Eckroade. Zu Rhein, and Hanson (1969) & & \\
\hline & & - & Barlow and Rennie, unpublished & & Chandler and Fisher (1963) \\
\hline \multirow{2}{*}{ Hamsters } & Golden & - & Marsh, Burger, Eckroade, Zu Rhein, and Hanson (1969) & 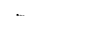 & Zlotnik (1963) \\
\hline & Chinese & & & -. & \\
\hline Ferrets & $\begin{array}{l}\text { Albino } \\
\text { Black }\end{array}$ & - & $\begin{array}{l}\text { Marsh, Burger, Eckroade, Zu Rhein, and Hanson (1969) } \\
\text { Marsh, Burger, Eckroade, Zu Rhein, and Hanson (1969) }\end{array}$ & & \\
\hline \multirow{2}{*}{\multicolumn{2}{|c|}{$\begin{array}{l}\text { Voles } \\
\text { Guinea pigs }\end{array}$}} & & 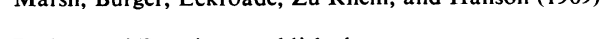 & … & Chandler (1971) \\
\hline & & - & Barlow and Rennie, unpublished & - & Zlotnik (1965) \\
\hline \multirow{2}{*}{\multicolumn{2}{|c|}{$\begin{array}{l}\text { Rabbits } \\
\text { Gerbils }\end{array}$}} & - & Barlow and Rennie, unpublished & - & Zlotnik (1965) \\
\hline & & & & & Gajdusek and Gibbs (1968) \\
\hline \multicolumn{2}{|c|}{ Skunk } & - & Marsh (1970), personal communication & & \\
\hline \multicolumn{2}{|l|}{ Raccoon } & - & Marsh (1970), personal communication & & \\
\hline \multicolumn{2}{|l|}{ Calves } & - & Marsh, Berger, Eckroade, Zu Rhein, and Hanson (1969) & & \\
\hline \multicolumn{2}{|l|}{ Chickens } & - & Marsh, Berger, Eckroade, Zu Rhein, and Hanson (1969) & & \\
\hline \multicolumn{2}{|l|}{ Cats } & - & Marsh, Burger, Eckroade, Zu Rhein, and Hanson (1969) & & \\
\hline \multirow{2}{*}{ Monkeys } & Rhesus & $?$ & Marsh, Burger, Eckroade, Zu Rhein, and Hanson (1969) & & \\
\hline & Chimpanzees & $\cdots$ & Eckroade, Zu Rhein, Marsh, and Hanson (1970) & - & $\begin{array}{l}\text { Gajdusek and Gibbs (1968) } \\
\text { Gajdusek and Gibbs (1968) }\end{array}$ \\
\hline
\end{tabular}

Table I Host species used in experimental transmission of mink encephalopathy and scrapie

\footnotetext{
1- Failure to transmit 3 - Successful transmission of $\}$ clinicc-pathological disease within the duraticn of the experiment.

? Absence of clinical disease but lesions present.
} 
logical evidence of disease was also reported in lymphoid tissues and/or brain of goats, calves, chickens, and mice. The incubation period in mink following injection of these tissues was often considerably extended, indicating very low titres in the inocula and suggesting that in these other hosts the agent did not replicate. There are two additional reports of failure to transmit mink encephalopathy to mice (Hadlow and Karstad, 1968; Dickinson, Fraser, and Meikle, 1972). Intracerebral injection of transmissible mink encephalopathy into guinea pigs and rabbits has failed to reproduce the disease in these species during an observation period of 32 months (Barlow and Rennie, unpublished).

On the other hand Zlotnik and Barlow (1967) reported successful transmission to a goat but failure to transmit to Swiss white mice. Later Barlow and Rennie (1970) using the same mink brain pool claimed a successful transmission to mice. These apparently anomalous results in mice and goats will be considered in more detail together with the results of further recent work.

\section{Mice}

On four separate occasions weanling mice of various strains were given intracerebral (ic) injections of supernatant of a transmissible mink encephalopathy mink brain pool obtained from Dr Burger $(10 \%$ suspension of brain tissue in normal saline, spun at $800 \mathrm{~g}$ for $2 \mathrm{~min}$ ). The experiments ran for 14 to 23 months but only in one experiment did the mice develop specific disease; half of a group of Porton mice contracted a condition resembling scrapie, both clinically and pathologically. The incubation periods in individual mice ranged from eight to 14 months. In further passage to four strains-Porton, C57BL, C57BR, and Moredun Swiss-all mice succumbed to a similar scrapie-like disease with incubation periods of from four and a half to seven and a half months (Barlow and Rennie, 1970).

Pools of brain tissue were prepared from each of these strains and aliquots sent to the Wisconsin workers who injected $10 \%$ suspensions of the Porton and Moredun Swiss mouse-brain pools intracerebrally into day-old Swiss mice and also into mink. The mice developed a disease indistinguishable from scrapie with uniform incubation periods of four months for the Porton and four and a half months for the Swiss mice-derived material, but in mink neither pool has yet caused any clinical disease in the 17 months of observation (Marsh, personal communication, 1971).

Aliquots of the same mouse pools were also given to Dr A. G. Dickinson, who tested them in conjunction with a 'blind' identification of scrapie agents from four different sources in tests which he and his colleagues have developed to detect differences between agents (Fraser and Dickinson, 1968; Dickinson, 1970; Dickinson and Meikle, 1971). Essentially in these tests, standard inocula injected into particular genotypes of mice produce disease with incubation periods and lesion profile arrays which are characteristic for each particular strain of the agent. Using this system the characteristics of both the Porton and Swiss mice transmissible mink encephalopathy inocula were indistinguishable from the ME7 strain of mouse scrapie originally isolated from Suffolk sheep (Dickinson, Fraser, Meikle, Barlow, and Rennie, 1972).

Thus a considerable amount of evidence has recently accumulated to suggest that the disease in the original group of Porton mice injected with mink brain may have been ME7 scrapie and the term 'putative transmissible mink encephalopathy' is applied hereafter to inocula derived from these mice.

\section{Goats}

Three young crossbred goats one of which, incidentally, was a hermaphrodite, were injected intracerebrally with a $10 \%$ saline suspension of $\mathrm{Dr}$ Burger's transmissible mink encephalopathy mink brain pool. The hermaphrodite developed a high stepping gait, ptosis on the left side, and apparent blindness in the right eye commencing about 20 months after injection. The disease was progressive and the goat was killed when showing severe disablement five months later. A focal lesion involving the occipital pole of the cerebrum, adjacent midbrain, and cerebellum on the left side-contralateral to the injection site - was anticipated but at necropsy none was found. The significant lesions were severe bilateral spongy transformation of the grey matter of the forebrain, diencephalon, and mesencephalon; less severe vacuolation of the ground substance was present in the medulla. These lesions were associated with intense astrogliosis. Neuronal vacuolation was also present in the medulla. Qualitatively these lesions resembled those of transmissible mink encephalopathy and scrapie though status spongiosis was much more severe than has been reported hitherto in scrapie in goats (Pattison, Gordon, and Millson, 1959; Hadlow, 1961; Zlotnik, 1961, 1962a and b; Zlotnik and Rennie, 1965).

One of the two remaining goats developed bilateral ptosis and slight hyperaesthesia and was killed 28 months after injection; histological examination revealed only mild status spongiosis of the corpora quadrigemina. The third goat was clinically normal throughout but when slaughtered 43 months after injection mild spongy changes 
were found in the cerebral cortex and amygdala (Barlow and Rennie, 1970).

Brain tissue from the hermaphrodite was passaged intracerebrally into three young goats all of which gradually became excitable and ataxic from about the ninth month after injection. These were destroyed after six months of slowly progressive disease and their pooled brains passaged a third time to three more young goats. These showed the same pattern and were killed 11 to 17 months after injection. The first of these was killed early in the clinical course of the disease because of a ruptured kidney sustained during fighting.

Brain tissue suspensions from the first and second goat passages were also injected intracerebrally into four strains of mice-Porton, C57BL, C57BR, and Moredun Swiss-and the mice were observed for 23 months. No cases occurred with the first pass-goatbrain, but with the second pass-goat-brain $2 / 20$ Porton, 2/20 C57BL, and 2/20 Swiss mice developed a scrapie-like disease with incubation periods ranging from eight to 19 months.

Four further goats, all by the same sire as the third pass transmissible mink encephalopathy goats and having the same maternal grandsire as two of them, were obtained. (These six animals had the highest degree of consanguinity of any of the goats used in these experiments.) The four goats were injected with $10 \%$ saline suspension of pooled brain tissue from the Porton mice which had succumbed to injections with transmissible mink encephalopathy brain pool (putative transmissible mink encephalopathy). All four developed a disease which was clinically indistinguishable from that already de- scribed for second and third pass transmissible mink encephalopathy direct from mink to goats.

The brains from these 13 goats, together with 16 goat brains representing four animals in each of four passages of ME7 scrapie, and 13 other goat brains from miscellaneous scrapie experiments, have recently been examined histologically in a random sequence.

A semiquantitative assessment of the degree of neuronal vacuolation $(-, \pm,+,++,+++)$, the presence (S) of spongy transformation of grey matter, and the degree of white matter vacuolation $(-, \pm$, $+,++,+++)$ was carried out for 40 anatomical sites in each brain. Nine sites giving varying scores and representing, hind-, mid-, and forebrain components (Fig. 1) were selected for numerical transformation of the scores $(-=1, \pm=2,+=3$, $++=4,+++=5, S=2)$. The data were grouped according to inoculum, mean values for each of the nine positions calculated and expressed as lesion profiles for each of the three inoculatransmissible mink encephalopathy, putative transmissible mink encephalopathy and ME7 scrapie. Only animals of similar clinical status were compared, the two older goats in the first pass and the nephrotic goat in the third pass of transmissible mink encephalopathy being omitted from these calculations.

The resulting profiles appear to differ (Fig. 1). Application of a non-parametric (Kruskal-Wallis) statistical test (Siegel, 1956) shows that the differences are significant at positions $4,7,8$, and 9 .

As the semiquantitative scoring system is liable to observer bias, the transmissible mink encephalo-

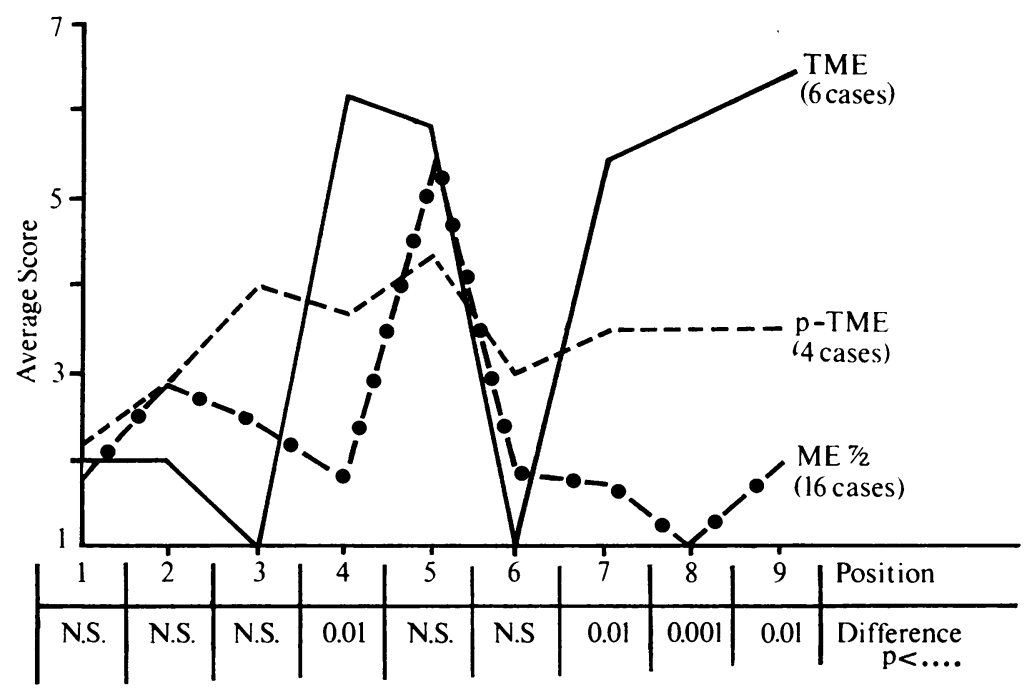

Fig. 1 Lesion profiles. Transmissible mink encephalopathy (TME), putative and $M E 7 / 2$ scrapie in goats. Positions: 1 hypoglossal nucleus; 2 raphemedulla; 3 red nucleus; 4 corpora quadrigemina; 5 paraterminal body (subcallosal gyrus); 6 dentate nucleus; 7 amygdaloid body; 8 cerebral cortex-inferior temporal gyrus; 9 hippocampus. 
pathy goats, an equal random sample of ME7 goats and all the putative transmissible mink encephalopathy goats have been examined quantitatively at positions 4 and 8 by an independent observer. All tissue holes in three fields ( $\times 600$ magnification) of standard haematoxylin-and-eosin-stained paraffin sections were counted with the exception of those clearly due to sectioning artefact or containing a recognizable tissue component such as a capillary.

In the inferior temporal cortex (position 8) tissue changes appeared to be uniformly distributed and the fields for counting were chosen at random. The differences between animals within groups were significant $(P<0.001)$ but despite these differences the transmissible mink encephalopathy group had significantly more holes than the ME7 group ( $P<$ 0.001 ). The counts of the putative transmissible mink encephalopathy goats all fell within the range of the scrapie animals.

However at position 4 the tissue changes were not uniformly distributed and for counting three adjacent fields along the perpendicular from the point of contact of the common tangent of the anterior colliculi were used. Three replicate counts of each section were made, the sections being re-randomized between counts. The least significant differences (LSD) for equal numbers of transmissible mink encephalopathy and ME7 brains were determined for 0.05 and 0.01 levels of probability and applied to the mean hole counts in each of the three areas of each group of goats (Table II).

Considering all three areas together ME7 differs significantly from transmissible mink encephalopathy and putative transmissible mink encephalopathy although the two latter do not differ significantly from each other except in the most superficial area of the colliculus (area 1). In area 3, transmissible mink encephalopathy does not differ significantly from ME7 whereas putative transmissible mink encephalopathy does. It must, however, be remembered that the putative transmissible mink encephalopathy results relate only to first passage goats.

These quantitative assessments of the pathology confirm and extend earlier subjective opinions (Zlotnik and Barlow, 1967; Barlow and Rennie,
1970) that goats injected with transmissible mink encephalopathy show different patterns of pathological change from those injected with strains of known scrapie agent. The position with regard to putative transmissible mink encephalopathy is more difficult to assess; at some sites the lesions accord with those of transmissible mink encephalopathy, at others with ME7, and at yet others the severity of the lesions appears to be intermediate between transmissible mink encephalopathy and ME7. In view of the findings in mice it seems likely that putative transmissible mink encephalopathy in goats is the result of infection with at least two agents one of which may be ME7. At first pass in goats, however, no particular agent is showing overall dominance and thus blocking the other(s). Brain samples of first and second passages of transmissible mink encephalopathy in goats were sent to Dr Marsh who injected the first passage material back into mink; it reproduced encephalopathy with incubation periods of six to seven months.

\section{General Discussion}

Transmissible mink encephalopathy and scrapie show a high degree of similarity with respect to clinical and pathological features of the disease process and the physico-chemical, immunological and biological properties of the agent. Since transmissible mink encephalopathy does not establish itself on a mink farm following an epizootic, mink may be an unnatural host (Burger and Hartsough, 1965 ) in much the same way as mice and hamsters are unnatural hosts with respect to scrapie. Indeed, Field (1969) has regarded transmissible mink encephalopathy as scrapie in mink. The difficulty in accepting this view, even tentatively, resides in the differing range of host species which are susceptible to these diseases. As indicated in Table I these include domestic and feral, exotic and commonplace species. In domestic and laboratory hosts controversial results have been obtained, possibly because such animals have been used most frequently.

Of the several occasions on which transmissible mink encephalopathy has been injected into mice, successful transmission has been claimed on only one

\begin{tabular}{|c|c|c|c|c|}
\hline & Area 1 & Area 2 & Area 3 & All Areas \\
\hline $\begin{array}{l}\text { Transmissible mink encephalopathy } \\
\text { ME7 } \\
\text { Putative transmissible mink encephalopathy }\end{array}$ & $\begin{array}{l}74 \cdot 0 \\
40 \cdot 0 \\
52 \cdot 2\end{array}$ & $\begin{array}{l}59 \cdot 4 \\
38 \cdot 8 \\
53 \cdot 5\end{array}$ & $\begin{array}{l}44 \cdot 4 \\
37 \cdot 1 \\
49 \cdot 7\end{array}$ & $\begin{array}{l}59 \cdot 3 \\
38 \cdot 6 \\
51 \cdot 8\end{array}$ \\
\hline
\end{tabular}

Table II Mean counts of 'holes' in three adjacent areas extending from the summits of the anterior colliculi (position 4)

$\operatorname{LSD} 0.05=8 \cdot 0, \operatorname{LSD} 0.01=10.8$ 
occasion called here putative transmissible mink encephalopathy; this transmission was not confirmed in repeat experiments using the same pool and mice from the same colony. At that successful first passage the 'take' was $50 \%$ and the incubation period variable. Sub-passage increased the take to $100 \%$, shortened and largely unified the incubation periods for several strains of mice in three separate laboratories. The consensus of opinion on the basis of incubation period, clinical signs, and pathology is that putative transmissible mink encephalopathy in mice is indistinguishable from scrapie. Examination of this agent in the incubation period/lesion profile system of Dickinson and his colleagues has further shown that putative transmissible mink encephalopathy in mice is indistinguishable from ME7 scrapie (Dickinson, Fraser, and Meikle, 1972). The quantitative assessment of goat material provides further evidence for a mixture of agents being present in the mouse tissue inoculum. The simplest explanation of these results is that the inoculum used for the first Porton mice was contaminated with ME7 scrapie at very low titre. This would account for the low take and long incubation period in mice at first passage with shortening of incubation period at sub-passage. In view of these observations further discussion of putative transmissible mink encephalopathy is unlikely to be profitable at this stage.

The goat passaged agent on the other hand raises a number of important points. First, was it 'incidental' that of the three goats injected with transmissible mink encephalopathy the only one to show a progressive clinical disorder was a hermaphrodite, or did its particular genetic make-up facilitate replication of the agent? Since the two other goats also showed mild lesions of the central nervous system of the same type the alternative possibility that the hermaphrodite was incubating a natural scrapie infection at the time of injection is an unlikely explanation.

Secondly, goat-passaged transmissible mink encephalopathy and goat-passaged ME7 each produced distinct lesion profiles. As the goats were of mixed breeding and the data for ME7 were assembled over a period of more than six years, the consistency of the profiles within each agent (eg, Fig. 2 for ME7) is mainly due to the characteristics of the agent itself and not the product of agent strain and host genotype such as has been shown for mice (Dickinson and Meikle, 1969, 1971).

These findings strongly suggest that transmissible mink encephalopathy and ME7 scrapie in goats are due to different agents. The failure to transmit firstpass goat-transmissible mink encephalopathy to mice reinforces this view. Material from the second pass goats did transmit a scrapie-like disease to six

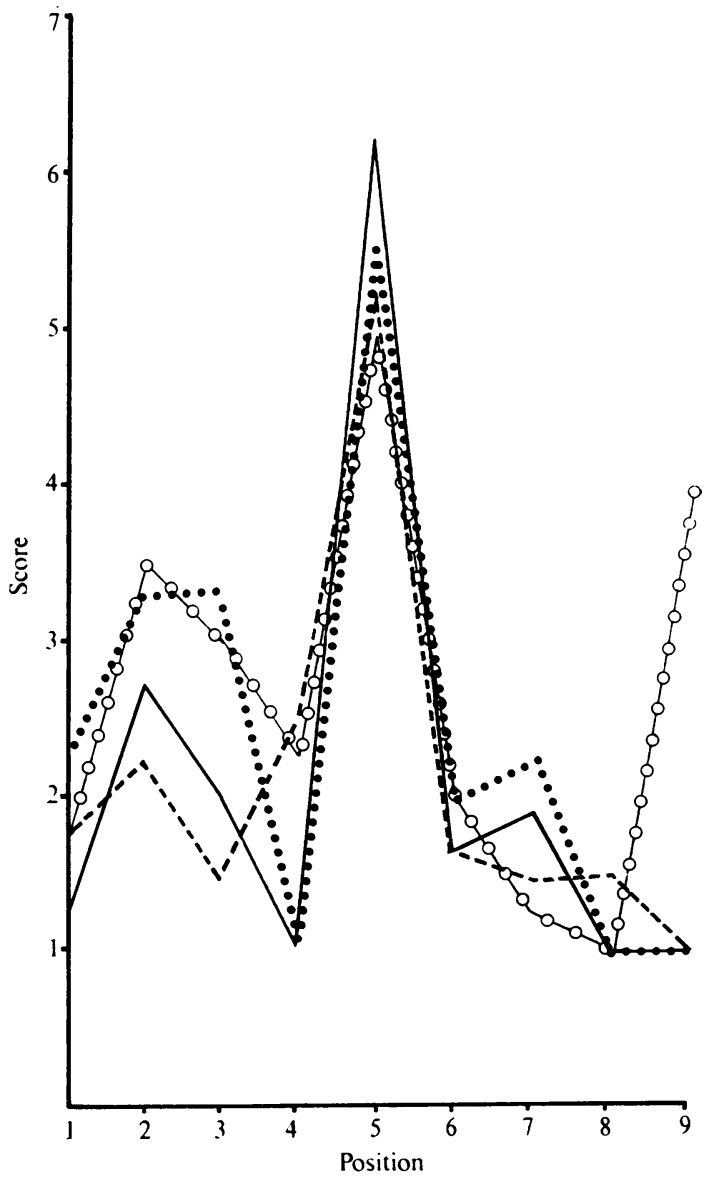

Fig. 2 Four serial passages of $M E 7 / 2$ in goats. First and fourth pass differ $(p<0.01$ at position 9$)$.

$\bigcirc-\bigcirc-\bigcirc$ first pass; - - - second pass; _- third pass; - fourth pass.

out of 80 mice. This may again represent low level contamination of the inoculum. If so it would most probably have occurred during the harvesting of the goat brains since the saw and bone forceps used for removal of the calvaria may have been used the previous day for the removal of the brain of a scrapie animal. At that time such instruments would not have received the four high-pressure autoclave treatments advocated for sterilizing scrapie materials (Dickinson, Fraser, Meikle, Barlow, and Rennie, 1972).

It is very unlikely that the original mink brain was contaminated with scrapie as this would readily replicate in goats, would have transmitted to mice at first passage and if such a hypothetical contaminant were the ME7 agent the lesion profile in goats should 
have come to resemble that of ME7 over three passages.

It is also unlikely that contamination occurred during preparation of the inoculum for mice, as disposable utensils and instruments were used and no scrapie inocula had been handled during the previous 15 days.

\section{Conclusions}

Present knowledge of host/agent relationships in most slow infections is at best incomplete. In one 'unnatural' host, the mouse, differences between biological properties of some strains of scrapie agent have been shown. Differences in measurable phenomena such as incubation period and lesion profile are determined by the interactions of the strain of agent and the genotype of the host.

Scrapie and transmissible mink encephalopathy have many similar properties some of which appear to be microbiologically unique. It is reasonable to assume that agent-strain/host-genotype interactions may also occur in transmissible mink encephalopathy. Serial passage of end-point dilutions in a single host-genotype have not yet been accomplished and thus there is no assurance that any current research on transmissible mink encephalopathy is being conducted with a single homogeneous strain of agent. This may account for some of the anomalous results which have been reported. In this context and on the question of identity between transmissible mink encephalopathy and scrapie it is important to establish which defined strains of scrapie agent will reproduce the former in mink. It would be prudent to conduct such experiments using mouse-passaged and original sheep-source materials in parallel: although there is as yet no evidence of modification of the agent by hosts of other species, most workers with scrapie have found differences in incubation period between first and subsequent passages, especially when the new species is an unnatural host. The biological significance of these differences is not understood, but may be important.

The new work reported in this paper has clarified the position with regard to earlier claims of successful transmission of mink encephalopathy to mice and goats. On present evidence, disease in mice (putative transmissible mink encephalopathy) should be considered to have arisen from contamination with ME7 scrapie.

It is clear, however, that the disease in the goat injected with mink brain is not ME7 scrapie. Also the distribution of the lesion and the intensity differ from those in all the forms of goat scrapie so far reported. Thus on present evidence the results represent genuine transmission of mink encephalopathy to goats and its reproduction in mink six to seven months after injection with goat brain may support this view. Alternatively the relatively long incubation period in the mink could indicate that original mink agent at low titre was carried over in the goat brain inoculum. Until the later goat passages have been similarly tested, the transmission of mink encephalopathy to goats repeated, and the homogeneity of the agent further investigated this question cannot be finally resolved. It is an important question to resolve as at present the goat appears to be a focal point of two diseases, transmissible mink encephalopathy and scrapie.

\section{References}

Barlow, R. M., and Rennie, J. C. (1970). Transmission experiments with a scrapie-like encephalopathy of mink. J. comp. Path., 80, 75-79.

Brander, N. R., and Palludan Birthe (1965). Leucoencephalopathy in mink. Acta vet. scand., 6, 41-51.

Brotherston, J. G., Renwick, C. C., Stamp, J. T., Zlotnik, I., and Pattison, I. H. (1968). Spread of scrapie by contact to goats and sheep. J. comp. Path., 78, 9-17.

Burger, D., and Hartsough, G. R. (1965). Encephalopathy of mink. II. Experimental and natural transmission. J. infect. Dis., 115 , 393-399.

Chandler, R. L. (1961). Encephalopathy in mice produced by inoculation with scrapie brain material. Lancet, 1, 1378-1379.

Chandler, R. L., and Fisher, J. (1963). Experimental transmission of scrapie to rats. (Letter). Lancet, $2,1165$.

Cuillé, J., and Chelle, P. L. (1936). La maladie dite tremblante du mouton est elle inoculable? C. R. Acad. Sci. (Paris), 203, 1552-1554.

Dickinson, A. G. (1970). Classification of scrapie agents based on histological and incubation period criteria in mice. In Proceedings of the VIth International Congress of Neuropathology, Paris, pp. 841-842.

Dickinson, A. G., Fraser, H., Meikle, V. M. H., Barlow, R. M., and Rennie, J. C. (1972). The comparison of some biological properties of four strains of scrapie agent and an agent passaged from TME injected mice. (In preparation.)

Dickinson, A. G., and Meikle, V. M. H. (1969). A comparison of some biological characteristics of mouse-passaged scrapie agents 22A and ME7. Genet. Res., 13, 213-225.

Dickinson, A. G., Fraser, H., and Meikle, V. M. H. (1972). An attempt to infect mice with transmissible mink encephaolpathy. (In preparation.)

Dickinson, A. G., and Meikle, V. M. H. (1971). Host-genotype and agent effects in scrapie incubation; change in allelic interaction with different strains of agent. Molec. gen. Genetics, 112, 73-79.

Dickinson, A. G., Young, G. B., Stamp, J. T., and Renwick, C. C. (1965). An analysis of natural scrapie in Suffolk sheep. Heredity (Lond.), 20, 485-503.

Eckroade, R. J., Zu Rhein, G. M., Marsh, R. F., and Hanson, R. P. (1970). Transmissible mink encephalopathy: experimental transmission to the squirrel monkey. Science, 169, 1088-1090.

Field, E. J. (1969). Slow virus infections of the nervous system. Int . Rev. exp. Path., 8, 129-239.

Fraser, H., and Dickinson, A. G. (1968). The sequential development of the brain lesions of scrapie in three strains of mice. J. comp. Path., 78, 301-311.

Gajdusek, D. C., and Gibbs, C. J., Jr. (1968). Slow latent and temperate virus infections of the central nervous system. Res. publ. Ass. nerv. ment. Dis., 44, 254-280.

Gardiner, A. C., and Marucci, A. A. (1969). Immunological responsiveness of scrapie infected mice. J. comp. Path., 79, 233-235.

Gordon, W. S., and Pattison, I. H. (1957). The experimental production of scrapie in goats. (Letter.) Vet. Rec., 69, 1444.

Hadlow, W. J. (1961). The pathology of experimental scrapie in the dairy goat. Res, vet. Sci., 2, 289-314.

Hadlow, W. J., and Karstad, L. (1968). Transmissible encephalopathy of mink in Ontario. Canad. vet.J., 9, 193-196.

Hanson, R. P., Eckroade, R. J., Marsh, R. F., Zu Rhein, G. M., 
Kanitz, C. L., and Gustafson, D. P. (1971). Susceptibility of mink to sheep scrapie. Science, 172, 859-861.

Hartsough, G. R., and Burger, D. (1965). Encephalopathy of mink. I. Epizootiologic and clinical observations. J. infect. Dis., 115, 387-392.

Innes, J. R. M., and Saunders, L. Z. (1962). In Comparative Neuropathology, p. 680. Academic Press, New York and London.

Marsh, R. F., Burger, D., Eckroade, R. J., Zu Rhein, G. M., and Hanson, R. P. (1969). A preliminary report on the experimental host range of the transmissible mink encephalopathy agent. J. infect. Dis., 120, 713-719.

Marsh, R. F., Burger, D., and Hanson, R. P. (1969). Transmissible mink encephalopathy: behaviour of the disease agent in mink. Amer. J. vet. Res., 30, 1637-1642.

Marsh, R. F., and Hanson, R. P. (1969). Physical and chemical properties of the transmissible mink encephalopathy agent. J. Virol., 3, 176-180.

Marsh, R. F., Pan, I. C., and Hanson, R. P. (1970). Failure to demonstrate specific antibody in transmissible mink encephalopathy. Infect. Immunol., 2, 727-730.

Pattison, I. H., Gordon, W. S., and Millson, G. C. (1959). Experimental production of scrapie in goats. J. comp. Path., 69, 300-312.

Siegel, S. (1956). Nonparametric Statistics for the Behavioral Sciences, pp. 184-193. McGraw-Hill, New York.

Sigurdsson, B. (1954). Rida a chronic encephalitis of sheep with general remarks on infections which develop slowly and some of their special characteristics. Brit. vet. J., 110, 341-354.

Stamp, J. T. (1967). Scrapie and its wider implications. Brit. med. Bull., 23, 133-137.

Thormar, H. (1971). Slow infections of the central nervous system. $Z$. Neurol., 199, 1-23 and 151-166.

Zlotnik, I. (1961). The histopath of the brain of goats affected with scrapie. J. comp. Path., 71, 440-448.

Zlotnik, I. (1962a). Pathology of scrapie: a comparative study of lesions in the brain of sheep and goats. Acta neuropath., Suppl. $1,61-70$.

Zlotnik, I. (1962b). A comparative study of early brain lesions of goats inoculated with scrapie goat brain by the intracerebra and the subcutaneous routes. J. comp. Path., 72, 366-373.

Zlotnik, I. (1963). Experimental transmission of scrapie to golden hamsters. (Letter.) Lancet, 2, 1072.

Zlotnik, I. (1965). Observations on the experimental transmission of scrapie of various origins to laboratory animals. In Slow, Latent, Temperate Virus Infections (NINDB Monograph, No. 2), edited by D. C. Gajdusek, C. J. Gibbs, Jr., and M. Alpers, pp. 237-248. National Institutes of Health, Washington, D.C.

Zlotnik, I., and Barlow, R. M. (1967). The transmission of a specific encephalopathy of mink to the goat. (Letter.) Vet. Rec., 81, 55-56.

Zlotnik, I., and Rennie, J. C. (1965). Experimental transmission of mouse passaged scrapie to goats, sheep, rats and hamsters. $J$. comp. Path., 75, 147-157. 